\title{
Avaliação da qualidade demandada e diretrizes de melhoria no processo de interação Universidade-Empresa
}

\author{
Ana Paula Mateia*, Márcia Elisa Echeveste ${ }^{\mathrm{b}}$, \\ Carla Schwengber ten Caten ${ }^{c}$, Ricardo Norberto Ayup Zouain ${ }^{d}$ \\ a*ana.matei@ufrgs.br, UFRGS, Brasil \\ becheveste@producao.ufrgs.br, UFRGS, Brasil \\ ctencaten@producao.ufrgs.br, UFRGS, Brasil \\ dricardo.ayup@ufrgs.br, UFRGS, Brasil
}

\begin{abstract}
Resumo
0 artigo apresenta o processo de interação Universidade-Empresa no âmbito da Universidade Federal do Rio Grande do Sul (UFRGS), sob a responsabilidade da Secretaria de Desenvolvimento Tecnológico (SEDETEC). 0 objetivo é identificar as demandas de qualidade no processo de interação UFRGS-Empresas parceiras e propor melhorias para este processo. As demandas são identificadas com base em uma pesquisa de mercado, sendo desdobradas em características de qualidade e procedimentos para atendimento, por meio do Quality Function Deployment (QFD). Posteriormente, são propostas sugestões de melhorias para a SEDETEC. Os principais resultados são: a identificação e a priorização da qualidade demandada pelo setor empresarial; a avaliação dos requisitos e dos procedimentos que atendem a estas demandas e a proposição de diretrizes para melhorias no serviço da SEDETEC, destacandose: ampliação e dinamização das formas de comunicação; criação de um sistema de indicadores de desempenho; e análise de mercado para as tecnologias desenvolvidas.
\end{abstract}

\section{Palavras-chave}

Interação Universidade-Empresa. Escritório de transferência de tecnologia. QFD.

\section{Introdução}

Uma das maneiras de se promover o desenvolvimento tecnológico é por meio da criação de uma estrutura e cultura nacional de interação entre as instituições de pesquisa e as empresas. A interação entre duas ou mais organizações pressupõe a existência de uma relação cooperativa, que pode depender da natureza da empresa e do seu mercado, e varia segundo as fontes, os custos e a intensidade das trocas de informações (ORGANIZAÇÃO..., 1997). Muitos países percebem essa interação como parte fundamental para a execução de suas políticas de ciência e tecnologia (C\&T), criando mecanismos para incentivar esta relação (SEGATTO, 1996; STAL, 1998; VASCONCELOS; FERREIRA, 2000), uma vez que as empresas não priorizam a pesquisa básica e nem possuem suficiente capacitação técnica para exercê-la.
Na maioria dos países, o responsável por viabilizar o desenvolvimento tecnológico nacional passa a ser o Estado, que estimula as interações entre instituições de pesquisa e as empresas do meio no qual estão inseridas. Neste contexto, destaca-se o papel das Instituições de Ciência e Tecnologia (ICTs) nacionais, tais como as universidades, como geradoras de novos conhecimentos e tecnologia (NIOSI, 1999; CRIPPS, et al. 1999; SHANE, 2004).

As universidades são uma importante fonte de "oportunidades científicas e tecnológicas" para a inovação. As empresas buscam distintas formas de atualização tecnológica nas ICTs, como a capacitação, treinamentos, serviços tecnológicos, patentes e outras possibilidades de interação, além da busca por profissionais altamente qualificados, acesso à 
estrutura física e tecnológica de laboratórios e centros de pesquisas. Por meio desta relação identifica-se um processo de aprendizagem e unificação de conhecimentos científicos e competências tecnológicas, articulando esforços entre os setores produtivo, governamental e as instituições de ensino e pesquisa (FREEMAN, 1995; SANTOS; KOVALESKI; PILATTI, 2008; SUZIGAN; ALBUQUERQUE, 2008).

0 objetivo das ICTs, no entanto, não é a transformação da tecnologia em produtos, processos ou serviços, nem mesmo a comercialização destes advindos da tecnologia desenvolvida. 0 objetivo é criar e viabilizar mecanismos para disponibilizar o conhecimento científico e tecnológico (como os escritórios de transferência de tecnologia) ao setor produtivo que, por sua vez, comercializa a tecnologia transformada em produtos e processos para a sociedade (EDQUIST, 1997; SHANE, 2004). 0 desenvolvimento tecnológico decorre do processo resultante da transferência de tecnologia, no qual uma empresa consegue absorver determinada tecnologia gerada nas ICT e transformar esta tecnologia em produtos ou processos capazes de gerar riqueza (CYSNE, 2005; AYUP-ZOUAIN, 2008).

No Brasil, a partir do marco legal estabelecido com a publicação da Lei de Inovação Tecnológica (n $n^{\circ}$ 10.973/04) (BRASIL, 2004) e do Decreto $n^{\circ} 5.563 / 05$, que regulamenta a referida Lei, as ICTs precisaram adequar suas estruturas administrativas para a criação de um Núcleo de Inovação Tecnológica (NIT), com a finalidade de gerir a política de inovação institucional, e com obrigações mínimas definidas pelo Governo. Na Universidade Federal do Rio Grande do Sul (UFRGS), a instância responsável pelo cumprimento desta política é a Secretaria de Desenvolvimento Tecnológico (SEDETEC).

A atuação da SEDETEC engloba: a análise jurídica dos instrumentos legais para prestação de serviços e acordos de parceria entre a Universidade e a sociedade (conforme previsto na Decisão n 193/11 e pela Portaria 2679/11 do Conselho Universitário da UFRGS); a gestão da propriedade intelectual e dos contratos de transferência de tecnologia (conforme Portaria $n^{\circ}$ 3064/98); da rede de incubadoras tecnológicas e do estímulo ao empreendedorismo. (UNIVERSIDADE..., 1998, 2011a,b). A partir desta atuação, a SEDETEC exerce um papel fundamental na instituição, que é o de gerir as interações com o setor empresarial, atuando na atividade intermediária da formalização dos processos de interação Universidade-Empresa.

Neste contexto, o objetivo deste trabalho é identificar as principais qualidades demandadas pelas empresas no processo de interação UniversidadeEmpresa e propor melhorias nos procedimentos de formalização da interação prestados pela SEDETEC.
A identificação das qualidades demandadas e dos procedimentos para a formalização da interação Universidade-Empresa não foi abordada em outros artigos. Este aspecto é relevante principalmente aos gestores de núcleos de inovação tecnológica das universidades, em especial das universidades públicas, devido às implicações legais e aos trâmites administrativos necessários para sua formalização.

Inicialmente, foi realizada uma pesquisa de mercado que contemplou as duas etapas do processo de interação: a primeira, "definição da instituição", que identificou as qualidades das demandas pelas empresas para a seleção da instituição parceira; e a segunda, "contratação da instituição", que identificou as demandas no momento de formalização da interação entre os parceiros.

As demandas identificadas foram desdobradas em requisitos necessários para atendê-las por meio da utilização do Quality Function Deployment (QFD). Posteriormente, foram propostas diretrizes de melhoria para o serviço prestado pela SEDETEC.

A seção 2 apresenta uma revisão sobre o processo de interação Universidade-Empresa e sobre o Quality Function Deployment (QFD); na seção 3, são apresentados os procedimentos metodológicos da pesquisa; na seção 4, é apresentado o modelo conceitual do QFD e, na seção 5, apresentam-se as conclusões do artigo.

\section{Interação Universidade-Empresa}

As interações entre os agentes - empresa, universidade e governo - formam a base de sistemas de inovação regionais, nacionais e internacionais, de maneira a viabilizar a competitividade e o desenvolvimento científico e tecnológico das empresas em seus diferentes setores, assegurando o desenvolvimento econômico e social do país por meio da interação e transferência de tecnologia (VEDOVELLO, 1997; MARCOVITCH, 1999; VASCONCELOS; FERREIRA, 2000; SEGATTO-MENDES, 2001).

As universidades têm a capacidade de geração de novos conhecimentos, adequados para solucionar problemas de diferentes setores na sociedade. As empresas têm a necessidade de inovar e melhorar seus produtos e processos para tornarem-se competitivas. Mowery e Sampat (2005) realizaram estudos sobre a importância da pesquisa universitária para os avanços tecnológicos e a interação entre universidade e empresas. Estes autores indicam alguns "produtos" importantes economicamente que resultam da pesquisa acadêmica, tais como: informações tecnológicas e científicas; equipamentos e instrumentação; capital humano; redes de capacidade científica e tecnológica e o desenvolvimento de protótipos de novos produtos e processos (PÓVOA, 2008). 
Constata-se assim que as universidades passaram a ocupar um lugar privilegiado e estratégico nos sistemas nacionais de inovação. Esta situação decorre, principalmente, pela sua capacidade na formação de profissionais altamente qualificados, bem como pela sua infraestrutura científica relacionada com a dimensão tecnológica, colocando-se no centro de uma dinâmica complexa de relações alinhadas, que se reforçam mutuamente (DAGNINO, 2003; ALBUQUERQUE; SILVA; PÓVOA, 2005; PÓVOA, 2008).

A transferência de tecnologia corresponde a um processo de passagem de conhecimentos e de competências específicas, desenvolvidas a partir da realização de pesquisas, geralmente desenvolvidas nas universidades, que tem por finalidade promover a capacitação tecnológica das empresas receptoras (MARCHIORI; COLENCl JUNIOR, 1998). De acordo com a Associação Nacional de Entidades Promotoras de Empreendimentos Inovadores (2002), a transferência de tecnologia significa o intercâmbio de conhecimentos e habilidades tecnológicas entre instituições de ensino superior e/ou centros de pesquisa e empresas. Segundo o Instituto Nacional de Propriedade Industrial (INSTITUTO..., 2008), a transferência de tecnologia é uma negociação econômica e comercial que desta maneira deve atender a determinados preceitos legais e promover o progresso da empresa receptora e o desenvolvimento econômico do país.

As organizações inovadoras estão conscientes dos benefícios e ganhos advindos da efetivação de parcerias externas, em especial para viabilizar determinadas necessidades tecnológicas, visando atender às demandas de mercado. As universidades centralizam o conhecimento e a interação com empresas viabiliza diferentes formas de agregar valor aos produtos, processos ou serviços, levando mais benefícios para a sociedade. Para o setor produtivo, as pesquisas e as tecnologias geradas nas universidades, ao serem transferidas, são fontes de novas possibilidades para empreender em novos mercados ou mesmo diversificá-los (DAUSCHA, 2008; SUZIGAN; ALBUQUERQUE, 2008).

Para Feldam et al. (2002), as universidades têm experimentado e adotado mecanismos alternativos de transferência de propriedade intelectual. A ideia de participação nas empresas como, por exemplo, o pagamento para o uso da propriedade intelectual da universidade são mecanismos emergentes. Acordos em que a universidade recebe a participação nos lucros de uma empresa em troca de prover à companhia o direito de uso dos direitos de invenção da universidade estão se tornando comum. A transferência de tecnologia tem múltiplos objetivos como determinantes da estratégia de propriedade intelectual, aproxima vínculos entre universidade e indústria, aumenta o prestígio da universidade e aumenta e acelera a transferência de tecnologia para o benefício econômico e social.

Para que essa conjuntura possa ser efetivada é necessário compreender os procedimentos de transferir o conhecimento científico para a sociedade, e os fatores que são demandados nesse processo. As ICTs têm o papel de realizar essa transferência e a correta interpretação dos procedimentos torna mais eficiente o avanço tecnológico e o desenvolvimento socioeconômico. Para melhorar a qualidade deste processo, a prospecção das demandas das empresas torna-se uma fonte de conhecimentos capaz de sinalizar os requisitos necessários para assegurar que o processo de interação atenda tanto aos objetivos estratégicos das empresas, como das instituições científicas e tecnológicas que estão envolvidas.

Perkmann e Walsh (2007) analisaram as práticas de pesquisa colaborativa, evidenciando que as relações universidades-indústrias são amplamente praticadas, mesmo existindo objetivos científicos distintos. Os autores concluem que a maioria das pesquisas relacionadas concentra-se sobre os efeitos das relações universidade-indústria, tais como patentes ou inovações na empresa, sem analisar a dinâmica organizacional destas relações. Sugerem a necessidade de uma agenda de pesquisa em duas áreas: pesquisa e combinação dos processos entre universidades e empresas, e a organização e gestão da relação colaborativa.

Identificadas as demandas, é possível desdobrá-las em características de qualidade ou requisitos do serviço necessários para o atendimento destas. Por sua vez, os requisitos do serviço estão relacionados aos procedimentos e recursos que devem ser assegurados pela instituição. Uma forma de entender esta rede de relações é por meio da ferramenta de planejamento da qualidade de QFD. Esta ferramenta tem como objetivo elucidar e estabelecer as relações de dependência entre demandas, processo e recursos, conforme é discutido a seguir.

\subsection{Quality Function Deployment - QFD}

O QFD ou Desdobramento da Função Qualidade é uma ferramenta de gestão que proporciona uma conectividade visual dos processos para ajudar a focar as necessidades dos clientes em todo o ciclo de desenvolvimento de um produto ou processo. Fornece os meios para traduzir as necessidades dos clientes em requisitos técnicos adequados para projetar a qualidade em cada fase do desenvolvimento do ciclo de vida, auxiliando a desenvolver produtos de qualidade superior e de forma mais orientada para o cliente. Embora a estrutura fornecida pelo QFD possa ser significativamente benéfica, não é uma ferramenta simples de usar (BOUCHEREAU; ROWLANDS, 2000; CARNEVALLI; CAUCHICK MIGUEL, 2007). 
0 QFD é um método utilizado para o desenvolvimento de produtos e serviços, cujo objetivo é definir as especificações de produtos ou serviços com base nas necessidades dos clientes (CAUCHICK MIGUEL, 2009). Os modelos conceituais do QFD são aplicados a partir de uma série de matrizes desenvolvidas com base nas informações ou na "voz do cliente", obtidas por uma pesquisa de mercado e outros canais de comunicação.

Segundo Carvalho (1997), surgiram diferentes variações do modelo original, criado por Akao na década de 60, entretanto, as mais difundidas são: i) Modelo ASI - American Supplier Institute (AMERICAN..., 1993); ii) Modelo GOAL/QPC (KING, 1989); iii) QFD-Estendido apresentado por Clausing e Pugh (1991); iv) QFD-Quatro ênfases apresentado por Akao (1990).

A versão mais conhecida nos EUA, adotada pelo American Supplier Institute (AMERICAN..., 1993), é uma versão simplificada e caracteriza-se por quatro desdobramentos principais: planejamento do produto, desdobramento dos componentes, planejamento do processo e planejamento da produção. Segundo Cheng e Melo Filho (2007), a versão disseminada pela GOAL/QPC (KING, 1989) distingue o QFD como um desdobramento ordenado de matrizes, não utilizando tabelas e não distinguindo modelos conceituais, sendo que, na visão japonesa, a definição de um modelo conceitual é necessária para a aplicação do QFD em ambientes industriais distintos. No Brasil, alguns praticantes têm utilizado as versões do ASI ou do King, porém essas versões são simplificações do original que limitam o alcance do resultado em toda sua plenitude (CARVALHO, 1997; CHENG; MELO FILHO, 2007).

0 QFD - Estendido é caracterizado pela existência de quatro fases: planejamento do produto, projeto, planejamento do processo e planejamento da produção, sendo que a segunda delas é constituída de várias matrizes e as demais de apenas uma matriz. O QFD das Quatro Ênfases caracteriza-se por quatro tipos de dimensões ou ênfases: qualidade, tecnologia, custo e confiabilidade, sendo que cada desdobramento é composto de várias matrizes. A escolha das matrizes utilizadas no modelo conceitual varia de acordo com tipo de desenvolvimento, objetivo do projeto e setor dos produtos ou serviços envolvidos. Essas duas versões do QFD se diferenciam basicamente pela condução da execução dos desdobramentos (CLAUSING, 1994; CHENG; SARANTÓPOULOS, 1995; AKAO, 1996; PEIXOTO; CARPINETTI, 1998).

Em um estudo realizado sobre a aplicação do QFD, Carnevalli e Cauchick Miguel (2007) identificaram a flexibilidade do método e a aplicabilidade em diferentes situações de produção de bens e serviços.
Desta maneira, foi possível analisar que sua aplicação não se limita ao desenvolvimento de produtos, processos e serviços, apresentando-se também como um interessante método de análise e correlação de informações. (CARNEVALLI; CAUCHICK MIGUEL, 2007; MENDONÇA, 2007).

Analisaram-se diferentes aplicações do QFD em serviços, tais como: i) desdobramentos da qualidade nos serviços de uma biblioteca para identificar os serviços e posteriormente propor um projeto de modernização (FERREIRA; RIBEIRO, 1995); ii) planejamento para melhorar a fidelização de clientes para um clube de Porto Alegre (RIBEIRO; CUNHA; ECHEVESTE, 2001); e iii) identificação dos requisitos do serviço de consultas eletivas do plantão médico da Policlínica Santa Clara da Irmandade Santa Casa de Misericórdia de Porto Alegre (BRATZ; CATEN; DANILEVICZ, 2001); iv) propor melhorias nos serviços em um curso de mestrado em Engenharia de Produção de uma instituição privada (MORAES; CAUCHICK MIGUEL, 2005). No entanto, não foram identificados estudos sobre a aplicação do QFD nos processos de interação Universidade-Empresa.

\section{Procedimentos metodológicos}

\subsection{Método de trabalho}

0 desenvolvimento do trabalho foi dividido em três macroetapas: i) Pesquisa de Mercado; ii) Desdobramento das demandas de qualidade em requisitos, utilizando o Modelo Conceitual do QFD proposto por Ribeiro, Echeveste e Danilevicz (2001); e iii) Diretrizes de melhorias para a SEDETEC. 0 modelo proposto por Ribeiro, Echeveste e Danilevicz (2001) para aplicação do QFD em serviços baseia-se em duas macroetapas: i) pesquisa de mercado; e ii) desdobramento da qualidade demandada em requisitos do serviço. A pesquisa de mercado é utilizada na etapa inicial do QFD e engloba a identificação do cliente, a pesquisa com os clientes e priorização dos itens da qualidade demandada.

A macroetapa Pesquisa de Mercado foi dividida em quatro etapas: i) planejamento da pesquisa de mercado; ii) pesquisa qualitativa para levantamento da qualidade demandada pelas empresas parceiras; iii) categorização das demandas em níveis primário, secundário e terciário - modelo de diagrama de afinidades; e iv) pesquisa quantitativa para priorização das demandas. A segunda macroetapa, o Desdobramento das Qualidades Demandadas em Requisitos do Serviço, foi realizada utilizando o modelo conceitual de Ribeiro, Echeveste e Danilevicz (2001), que contemplou a utilização de cinco matrizes principais: a) matriz da qualidade composta com base no desdobramento da qualidade demandada e dos requisitos da qualidade; b) matriz dos procedimentos - baseada no desdobramento e etapas 
dos procedimentos dos serviços; c) matriz de recursos humanos; d) matriz de recursos de infraestrutura física envolvidos para a realização dos procedimentos; e e) matriz de custos. Uma vez definidos os requisitos prioritários, foi realizada a terceira macroetapa que contempla as Diretrizes de melhoria para o processo de prestação de serviços da SEDETEC.

\section{Apresentação dos resultados}

Conforme descrito pelo método de trabalho, o estudo foi desenvolvido em três macroetapas, detalhadas a seguir.

\subsection{Pesquisa de mercado}

A pesquisa de mercado contemplou uma fase qualitativa e uma fase quantitativa, explicitadas a seguir.

\subsubsection{Pesquisa qualitativa para levantamento da qualidade demandada pelas empresas parceiras}

0 objetivo da pesquisa qualitativa foi identificar as principais qualidades demandadas no processo da interação Universidade-Empresa nas duas etapas do processo de interação: i) "definição da instituição", que identificou quais as qualidades demandadas pelas empresas para a seleção da instituição parceira; e ii) "contratação da instituição", que identificou as demandas no momento de formalização dos projetos de interação entre os parceiros. Os resultados foram avaliados, visando às possibilidades de melhoria no processo de formalização da interação UniversidadeEmpresa realizadas pela SEDETEC.

Foram utilizadas entrevistas estruturadas, aplicando-se um questionário aberto definido com o apoio de especialistas. Estes especialistas deveriam conhecer profundamente os procedimentos e mecanismos de interação entre a universidade e empresas; possuir conhecimento em relação às principais legislações internas (da UFRGS) e externas (leis federais) que implicam neste processo; bem como ter experiência no desenvolvimento e execução de projetos de interação. Para atender estes critérios, foram selecionados três especialistas que atuam no processo de formalização do relacionamento de empresas com a universidade (servidores que atuam na SEDETEC, conhecedores do processo de formalização da interação entre a UFRGS e empresas), sendo um o servidor responsável pela rede de incubadoras da UFRGS; um servidor da área de propriedade intelectual; e o próprio Secretário de Desenvolvimento
Tecnológico da UFRGS. Dentre aqueles que deveriam ter experiência em projetos de interação, foram selecionados três pesquisadores docentes da UFRGS que desenvolvem projetos cooperativos e de prestação de serviços com empresas, com base em um sistema de dados da própria SEDETEC. Estes pesquisadores atuam com empresas em projetos de grande porte', com prazos de execução acima de 24 meses, e abrangendo três das principais unidades acadêmicas com maior número de projetos de interação, quais sejam: Escola de Engenharia, Instituto de Química e Instituto de Geociências. Além destes critérios, estes docentes possuem projetos de interação com empresas há pelo menos 5 anos. Foram envolvidos na pesquisa também dois pesquisadores alunos, um mestrando e um doutorando, os quais possuíam como temas de estudo assuntos sobre propriedade intelectual, transferência de tecnologia e interação entre universidades e empresas.

0 questionário foi validado pela aplicação de um pré-teste respondido por docentes/pesquisadores e dirigentes de empresas que atuam em projetos de interação com a UFRGS. Estes dirigentes possuem ampla interação com a universidade, em termos de projetos desenvolvidos (projetos de grande porte, que demandam o envolvimento tanto dos pesquisadores da UFRGS como da empresa, infraestrutura tecnológica e com prazos de realização acima de 24 meses), assim como vínculos pessoais em termos de qualificação profissional (como ex-alunos de graduação e pós-graduação).

0 questionário final com as correções sugeridas no pré-teste foi aplicado às empresas parceiras, definidas por critério de amostragem não probabilística por julgamento, integrando à amostra empresas parceiras de grande porte e empresas incubadas (empresas de micro e pequeno porte). As empresas realizam a interação com a universidade de duas maneiras: por meio da prestação de serviços e/ou ações de parceria e por meio da incubação de empresas. Todas tinham como característica comum possuírem estratégias de inovação tecnológica e de pesquisa e desenvolvimento (P\&D). Os respondentes foram diretores ou gerentes de $P \& D$ ou os sócios das empresas.

\subsubsection{Organização das demandas por afinidade}

A organização e a categorização das demandas por afinidade foram elaboradas com base nas respostas coletadas no questionário qualitativo. Estas demandas

\footnotetext{
Em relação ao porte dos projetos na UFRGS, são considerados de pequeno porte aqueles até $R \$ 250$ mil, conforme a Portaria $n^{\circ}$ 2060/2006. A título de definição para esta pesquisa, foram determinados projetos de médio porte aqueles acima de $R \$ 250$ mil até $R \$ 1$ milhão; e de grande porte aqueles projetos acima de $\mathrm{R} \$ 1$ milhão.
} 
foram categorizadas de maneira a agrupá-las nos níveis primário, secundário e terciário de detalhe. 0 agrupamento foi realizado pelos mesmos especialistas que auxiliaram na elaboração do questionário, seguindo o critério de afinidade entre os termos. 0 resultado é apresentado na forma de um Diagrama de Afinidade da Qualidade Demandada apresentado no Quadro 1.

\subsubsection{Pesquisa quantitativa para priorização das demandas de qualidade}

Para priorizar as demandas é importante que as empresas discriminem quais as demandas essenciais para o serviço. Um recorte das questões da pesquisa quantitativa é apresentado no Quadro 2. As questões de 1 a 5 referem-se ao grau de importância dos itens de qualidade demandada do nível terciário avaliado através da atribuição de nota utilizando-se uma escala de 1 a 5 . A questão 6 questiona a ordem de importância do nível secundário, avaliado através da ordenação dos 5 níveis secundários. A análise das notas atribuídas pelos respondentes foi realizada considerando simultaneamente todas as empresas, independente do seu porte.

Na sequência, os pesos atribuídos ao nível secundário foram transformados em pesos percentuais e, posteriormente, distribuídos proporcionalmente aos itens terciários. Desta forma, foi assegurado que cada demanda do nível terciário obtivesse um peso dependente do nível secundário ao qual ele pertence. Este peso é denominado de Índice de Importância da Qualidade Demandada $\left(I D_{i}\right)$.

A Tabela 1 apresenta a priorização dos itens secundários questionados na questão 6 .

Analisando a Tabela 1, verifica-se que os fatores mais relevantes para o cliente "empresa parceira" são os que caracterizam a "definição da instituição" como: i) estrutura disponível; ii) qualificação dos recursos humanos que serão envolvidos na parceria; e iii) gestão do projeto pela universidade.

A estrutura da UFRGS conta, em 2009, com 2.114 docentes (sendo 77\% doutores), 500 laboratórios, 625 grupos de pesquisa, além de técnicoadministrativos e pesquisadores/alunos dos 69 cursos de graduação e dos 140 programas de pós-graduação oferecidos pela instituição. Considerando que a SEDETEC é responsável pela gestão dos processos de formalização das parcerias, foi aplicado o modelo conceitual do QFD e realizado o desdobramento da qualidade em requisitos do processo somente para a etapa de "contratação da instituição".

Quadro 1. Diagrama de afinidade da qualidade demandada.

\begin{tabular}{|c|c|c|}
\hline \multicolumn{3}{|c|}{ Árvore da Qualidade Demanda pelas Empresas na Interação com a Universidade } \\
\hline Primário & Secundário & Terciário \\
\hline \multirow{15}{*}{$\begin{array}{c}\text { Bom relacionamento na interação } \\
\text { da UFRGS-Empresas parceiras } \\
\text { - Aspectos na "definição da } \\
\text { instituição" }\end{array}$} & \multirow{5}{*}{$\begin{array}{l}\text { Estrutura da } \\
\text { Universidade }\end{array}$} & Disponibilizar o acesso aos laboratórios e equipamentos exclusivos \\
\hline & & Possuir tecnologias de ponta \\
\hline & & Possibilitar o acesso às tecnologias de ponta \\
\hline & & Ter credibilidade, reconhecimento, marca \\
\hline & & Ter um bom histórico de parcerias \\
\hline & \multirow{5}{*}{$\begin{array}{l}\text { Recursos humanos - } \\
\text { equipe }\end{array}$} & Ter qualificações e competências dos profissionais envolvidos \\
\hline & & Ter responsabilidade e comprometimento da equipe \\
\hline & & Ter conhecimento tecnológico e inovador (pró-ativo) \\
\hline & & Ter agilidade no cumprimento dos prazos \\
\hline & & Compartilhar as informações \\
\hline & \multirow{5}{*}{$\begin{array}{l}\text { Características de qualidade } \\
\text { na gestão do projeto }\end{array}$} & Ter boa relação custo-benefício do investimento \\
\hline & & Boa apresentação da proposta e documentação concisa \\
\hline & & Definir claramente as reponsabilidades \\
\hline & & Definir claramente a especificação das atividades \\
\hline & & Definir claramente os prazos \\
\hline \multirow{10}{*}{$\begin{array}{c}\text { Bom relacionamento na interação } \\
\text { da UFRGS-Empresas parceiras } \\
\text { - Aspectos na “contratação da } \\
\text { instituição" }\end{array}$} & \multirow{5}{*}{$\begin{array}{c}\text { Caracteristicas de qualidade } \\
\text { e eficiência no processo } \\
\text { da interação }\end{array}$} & Ter comunicação aberta entre os envolvidos \\
\hline & & Ser transparente e ética na relação \\
\hline & & Ser flexivel \\
\hline & & Simplificar a relação (agilizar, desburocratizar e ser acessível) \\
\hline & & Manter sigilo e confidencialidade \\
\hline & \multirow{5}{*}{$\begin{array}{l}\text { Características do auxílio } \\
\text { da SEDETEC para a } \\
\text { transferência de tecnologia } \\
\text { e propriedade intelectual }\end{array}$} & Divulgar tecnologias disponíveis para transferência \\
\hline & & Identificar profissionais especialistas para consultorias e assessoria técnica \\
\hline & & Auxiliar na identificação de possibilidades de incubação de empresas \\
\hline & & Auxiliar no processo de patenteamento \\
\hline & & Identificar possibilidades de transferência de tecnologia para empresas \\
\hline
\end{tabular}


Quadro 2. Questionário quantitativo (recorte).

Este questionário visa a analisar a percepção da qualidade e
bom relacionamento da interação universidade e empresas. Por
favor, defina qual a ordem de importância dos itens abaixo para
a definição da qualidade desta interação? 1 = mais importante e
5 = menos importante.

\begin{tabular}{|l|l|}
\hline $\begin{array}{l}\text { 5) Em relação às caracteristicas do auxilio da SEDETEC } \\
\text { para transferência de tecnologia e PI: }\end{array}$ & 1 a 5 \\
\hline Divulgar tecnologias disponíveis para transferência & \\
\hline $\begin{array}{l}\text { Identificar profissionais especialistas para consultorias e } \\
\text { assessoria técnica }\end{array}$ & \\
\hline $\begin{array}{l}\text { Auxiliar na identificação de possibilidades de Incubação } \\
\text { de Empresas }\end{array}$ & \\
\hline Auxiliar no processo de patenteamento & \\
\hline $\begin{array}{l}\text { ldentificar possibilidades de transferência de tecnologia } \\
\text { para empresas }\end{array}$ & \\
\hline $\begin{array}{l}\text { 6) Numere estes elementos na ordem de maior } \\
\text { importância: }\end{array}$ & 1 a 5 \\
\hline Estrutura da Universidade & \\
\hline Recursos Humanos - pesquisadores da Universidade & \\
\hline $\begin{array}{l}\text { Características de qualidade na gestão do projeto pela } \\
\text { Universidade }\end{array}$ & \\
\hline $\begin{array}{l}\text { Características de qualidade e eficiência no processo da } \\
\text { interação com a Universidade: }\end{array}$ & \\
\hline $\begin{array}{l}\text { Características do auxílio da SEDETEC para transferência } \\
\text { de tecnologia e propriedade intelectual }\end{array}$ & \\
\hline
\end{tabular}

\subsection{Desdobramento das demandas em requisitos, utilizando o Modelo Conceitual do $Q F D$}

0 modelo proposto por Ribeiro, Echeveste e Danilevicz (2001), utilizado para desdobrar as demandas de qualidade da etapa de "contratação da instituição" em requisitos do processo, pode ser visualizado na Figura 1.

0 preenchimento das matrizes foi realizado por um grupo de especialistas envolvidos no processo de interação da universidade com empresas e acadêmicos da pós-graduação que colaboraram para a aplicação do referido modelo.

\subsubsection{Matriz da qualidade}

A matriz da qualidade relaciona as demandas da qualidade da etapa de "contratação da instituição", priorizadas pela pesquisa de mercado quantitativa, com os requisitos do processo ou características da qualidade necessárias para o atendimento destas demandas.

\subsubsection{Priorização das demandas da qualidade}

No QFD, a opinião do cliente deve ser o principal condutor das decisões. Contudo, segundo Ribeiro, Echeveste e Danilevicz (2001), o Índice de Importância da Qualidade Demandada $(I D)$ resultante da pesquisa
Tabela 1. Priorização dos itens secundários.

\begin{tabular}{|c|c|c|c|}
\hline $\begin{array}{l}\text { Etapas do } \\
\text { processo }\end{array}$ & Nível secundário & $I D_{i}$ & Peso (\%) \\
\hline \multirow{4}{*}{$\begin{array}{l}\text { "Definição da } \\
\text { Instituição" }\end{array}$} & Estrutura da Universidade & 4,83 & 26,03 \\
\hline & Recursos Humanos - equipe & 5,33 & 28,73 \\
\hline & $\begin{array}{l}\text { Características de qualidade } \\
\text { na gestão do projeto }\end{array}$ & 4,28 & 23,07 \\
\hline & Total & & 77,83 \\
\hline \multirow{4}{*}{$\begin{array}{c}\text { "Contratação } \\
\text { da Instituição" }\end{array}$} & $\begin{array}{l}\text { Características de qualidade } \\
\text { e eficiência no processo } \\
\text { da interação }\end{array}$ & 2,20 & 11,85 \\
\hline & $\begin{array}{c}\text { Características do auxílio da } \\
\text { SEDETEC para transferência } \\
\text { de tecnologia e propriedade } \\
\text { intelectual }\end{array}$ & 1,92 & 10,32 \\
\hline & Total & & 22,17 \\
\hline & & 18,57 & 100,00 \\
\hline
\end{tabular}

Fonte: Elaborada pelo autor.

de mercado quantitativa deve ser revisto considerando dois aspectos: i) avaliação competitiva $\left(M_{j}\right)$, a qual refere-se à comparação do desempenho com a concorrência, com escalas definidas de 0,5 a 2,0, representando respectivamente Muito acima da concorrência a Muito abaixo da Concorrência; e ii) avaliação estratégica $(E)$, também com escalas de 0,5 a 2,0, representando respectivamente Importância muito pequena a Importância muito grande.

A Equação 1 demonstra o cálculo do índice de Importância da Qualidade Demandada Revisto $\left(I D_{i}^{*}\right)$.

$I D_{i}^{*}=I D_{i} \times \sqrt{M_{i}} \times \sqrt{E_{i}}$

Onde:

- $I D_{i}^{*}=$ Importância da qualidade demandada revista;

- $I D_{i}=$ Importância da qualidade demandada;

- $M_{i}=$ Avalição competitiva dos itens de qualidade demandada;

- $E_{i}=$ Avaliação estratégica dos itens de qualidade demandada.

As demandas da qualidade revistas, conforme o Índice de Importância da Qualidade Demandada Revisto $\left(I D_{i}^{*}\right)$, podem ser vistas na Figura 2.

Conforme a Figura 2, as principais demandas com maior priorização revista foram: i) divulgação de tecnologias disponíveis para a transferência; ii) simplificação da relação; e iii) identificação das possibilidades de transferência de tecnologia para as empresas.

\subsubsection{Priorização das características da qualidade ou requisitos do serviço}

Inicialmente, foram listadas as características da qualidade na prestação dos serviços da SEDETEC. Estas 
(1)

\section{Questionário} (categorização das demandas)
ID

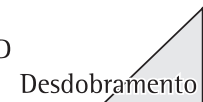
da gualidade demandada

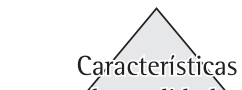
de qualidade

(2)

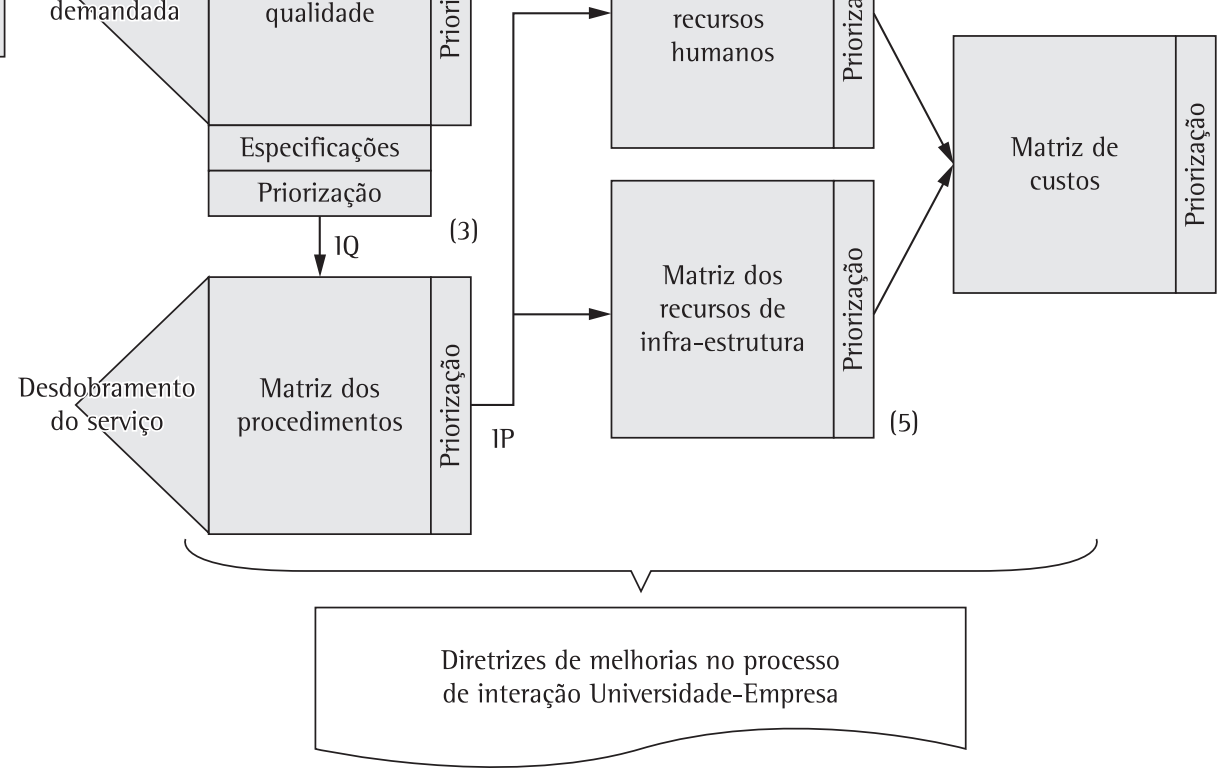

Figura 1. Modelo conceitual proposto por Ribeiro, Echeveste e Danilevicz (2001).

Divulgar tecnologias disponíveis para transferência

Simplificar a relação (agilizar, desburocratizar e ser acessível) Identificar possibilidades de transferência de tecnologia para empresas

Ter comunicação aberta entre os envolvidos Ser transparente e ética na relação

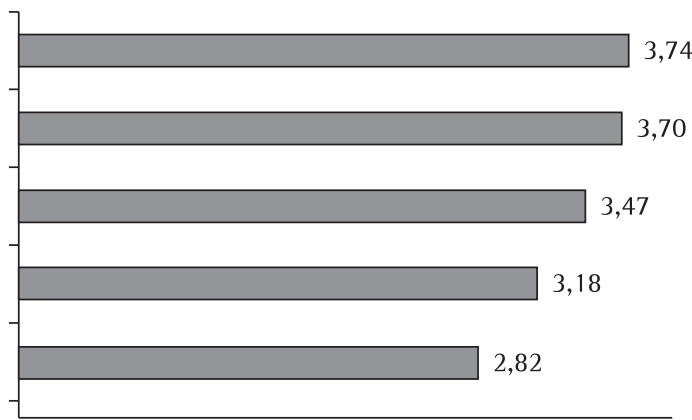

Figura 2. Priorização segundo o Índice de Importância da Qualidade Demandada Revisto ( $\left.I D_{i}^{*}\right)$ (recorte).

características da qualidade representam requisitos objetivos do serviço e passíveis de mensuração. Para identificar as características da qualidade ou requisitos do serviço prioritários, foi utilizada a Matriz da Qualidade, apresentada no Quadro 3. Para cada característica de qualidade, listada na coluna, foi questionado o quanto ela influenciava no atendimento das qualidades demandadas, listadas nas linhas, atribuindo-se um grau de relacionamento $\left(D Q_{i j}\right)$, utilizando-se uma escala de pesos 1 , 3 e 9, representando respectivamente: relação fraca, média ou forte. Este mesmo procedimento foi realizado nas demais matrizes do QFD.

A Importância Técnica das Características de Qualidade $\left(1 Q_{j}\right)$ é calculada por meio da Equação 2.

$1 Q_{j}=\sum_{j=1}^{n} D Q_{i j} \times I D_{i}^{*}$

Onde:

- $I Q_{j}=$ Importância Técnica das Características de Qualidade; 
- $D Q_{i j}=$ Grau de intensidade do relacionamento entre a característica de qualidade e a qualidade demandada;

- $I D_{i}^{*}=$ Importância da qualidade demandada revista. 0 Índice de Importância Técnica das Características da Qualidade $\left(1 Q_{j}\right)$ é revisto considerando dois índices: i) Análise Competitiva $\left(B_{j}\right)$ com escala de 0,5 a 2,0, sendo respectivamente Acima da Concorrência a Muito Abaixo da Concorrência; e ii) Análise da Dificuldade de Atuação $\left(D_{j}\right)$ nas melhorias, com escala também de 0,5 a 2,0 sendo, respectivamente, Muito Difícil a Fácil de atuar. A partir destes índices de correção, a importância pôde ser reavaliada. A Equação 3 apresenta o cálculo do Índice de Importância Técnica das Características da Qualidade Revisto $\left(I Q_{j}^{*}\right)$ :

$I Q_{j}^{*}=1 Q_{j} \times \sqrt{B_{j}} \times \sqrt{D_{j}}$

Onde:

- $l Q_{j}^{*}=$ Importância técnica das características da qualidade revista;

- $l Q_{J}=$ Importância técnica das características da qualidade;

- $D_{j}=$ Avaliação da dificuldade de atuação;

- $B_{J}=$ Avaliação da competitividade.
As características da qualidade priorizadas conforme o Índice de Importância Técnica das Características da Qualidade Revisto $\left(I Q_{j}^{*}\right)$, podem ser vistas na Figura 3.

Conforme a Figura 3, a característica de qualidade com maior priorização foi o número de pedidos de cotitularidade em patentes existentes quando há o desenvolvimento conjunto de tecnologias passíveis de proteção. As demais características priorizadas, como o contato com as empresas, o número de empresas incubadas, as publicações de editais para o licenciamento tecnológico, o atendimento a potenciais empresários e os registros de propriedade intelectual estão diretamente relacionadas aos processos de transferência de tecnologia.

\subsubsection{Matriz dos procedimentos de prestação de serviços}

A fim de priorizar os procedimentos do ciclo de serviços realizados pela SEDETEC, que auxiliam no atendimento das características da qualidade demandada, foi desenvolvida a Matriz de Procedimentos, conforme ilustrado no Quadro 4, sendo possivel avaliar a contribuição de cada procedimento na qualidade dos serviços.

Quadro 3. Matriz da qualidade (recorte).

\begin{tabular}{|c|c|c|c|c|c|c|c|c|c|c|c|c|}
\hline Matriz da qualidade & $\ddot{\varrho}$ & 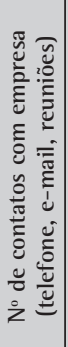 & 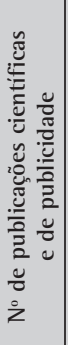 & 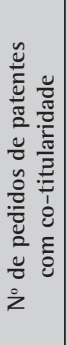 & 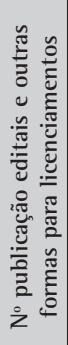 & 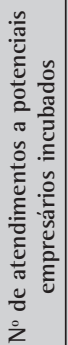 & 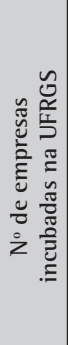 & 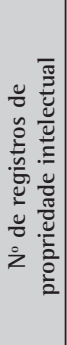 & 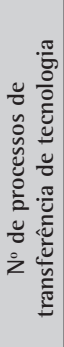 & 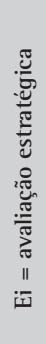 & 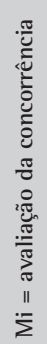 & 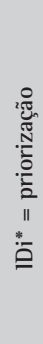 \\
\hline Ter comunicação aberta entre os envolvidos & 2,59 & 9 & 3 & 3 & 3 & 3 & 3 & 3 & 9 & 1,5 & 1,0 & 3,2 \\
\hline Ser transparente e ética na relação & 2,82 & 9 & 3 & 9 & 1 & 1 & 3 & 3 & 3 & 2,0 & 0,5 & 2,8 \\
\hline Ser flexível & 1,80 & 9 & 3 & 3 & & 3 & 3 & 3 & 3 & 1,0 & 1,5 & 2,2 \\
\hline Simplificar a relação (agilizar, desburocratizar e ser acessível) & 2,47 & 9 & 1 & 1 & 3 & 1 & 1 & 1 & 3 & 1,5 & 1,5 & 3,7 \\
\hline Manter sigilo e confidencialidade & 2,18 & 9 & 9 & 9 & 9 & 3 & 3 & 9 & 3 & 2,0 & 0,5 & 2,2 \\
\hline Divulgar tecnologias disponíveis para transferência & 2,64 & 1 & 9 & 9 & 9 & 3 & 9 & 9 & 9 & 2,0 & 1,0 & 3,7 \\
\hline $\begin{array}{l}\text { 1dentificar profissionais especialistas para consultorias e } \\
\text { assessoria técnica }\end{array}$ & 2,01 & 1 & 3 & 1 & & 3 & 3 & 3 & 3 & 1,0 & 0,5 & 1,4 \\
\hline $\begin{array}{l}\text { Auxiliar na identificação de possibilidades de lncubação } \\
\text { de empresas }\end{array}$ & 1,61 & & & 3 & 3 & 9 & 9 & 3 & 9 & 1,0 & 1,0 & 1,6 \\
\hline Auxiliar no processo de patenteamento & 1,23 & & 9 & 9 & 9 & 3 & 3 & 9 & 9 & 1,5 & 1,0 & 1,5 \\
\hline $\begin{array}{l}\text { 1dentificar possibilidades de transferência de tecnologia } \\
\text { para empresas }\end{array}$ & 2,83 & 1 & 9 & 9 & 9 & 9 & 9 & 9 & 9 & 1,5 & 1,0 & 3,5 \\
\hline
\end{tabular}

Importância técnica das características da qualidade

Avaliação da competitividade

Avaliação da dificuldade de atuação

Importância técnica das características da qualidade revista

\begin{tabular}{c|cccccccc}
\cline { 2 - 8 }$I Q_{j}$ & 11,4 & 11,0 & 12,8 & 10,3 & 8,3 & 10,4 & 11,5 & 13,2 \\
$B_{j}$ & 1,0 & 0,5 & 1,0 & 1,5 & 1,0 & 1,0 & 1,0 & 0,5 \\
$D_{j}$ & 1,5 & 2,0 & 1,5 & 1,0 & 2,0 & 1,5 & 1,0 & 1,5 \\
$I Q_{j}^{*}$ & 1,40 & 1,10 & 1,56 & 1,26 & 1,17 & 1,27 & 1,15 & 1,14 \\
\cline { 2 - 6 } & OBS: Os resultados do $1 Q_{j}$ foram divididos por 10.
\end{tabular}


0 preenchimento desta matriz foi realizado questionando-se o quanto cada procedimento, linha da matriz, auxilia no atendimento das características da qualidade $\left(I Q_{j}^{*}\right)$, coluna da matriz, atribuindo-se um grau de intensidade $\left(P Q_{i j}\right)$, utilizando-se a escala 1,3 e 9 . A priorização dos procedimentos $(I P)$ é calculada pela Equação 4.

$I P_{i}=\sum_{j=1}^{n} P Q_{i j} \times I Q_{j}^{*}$

\section{Onde:}

- $I P_{i}=$ Importância dos procedimentos;

- $P Q_{i j}=$ Grau de intensidade do relacionamento entre os procedimentos e as características de qualidade;
- $1 Q_{j}^{*}=$ Importância técnica das características de qualidade revista.

A importância de cada procedimento $\left(I P_{i}\right)$ foi ponderada por dois índices: i) Dificuldade de Implantação $\left(F_{i}\right)$; e ii) Tempo de Implantação $\left(T_{i}\right)$ de possiveis melhorias, utilizando-se uma escala de 0,5 a 2,0 para representar Muito Difícil $(0,5)$ a Fácil Implantação $(2,0)$ e Muito Grande $(0,5)$ a Pequeno $(2,0)$ tempo de implantação. A Equação 5 apresenta o Índice de Importância dos Procedimentos Revisto $\left(I P_{i}^{*}\right)$ :

$I P_{i}^{*}=I P_{i} \times \sqrt{F_{i}} \times \sqrt{T_{i}}$

$\mathrm{N}^{\circ}$ de pedidos de patentes com co-titularidade $\mathrm{N}^{\circ}$ de contatos com empresa (telefone, e-mail, reuniões) $\mathrm{N}^{\circ}$ de empresas incubadas na UFRGS $\mathrm{N}^{\circ}$ publicações editais e outras formas para licenciamentos $\mathrm{N}^{\circ}$ de atendimentos a potenciais empresários incubados $\mathrm{N}^{\circ}$ de registros de propriedade intelectual $\mathrm{N}^{\circ}$ de processos de transferência de tecnologia

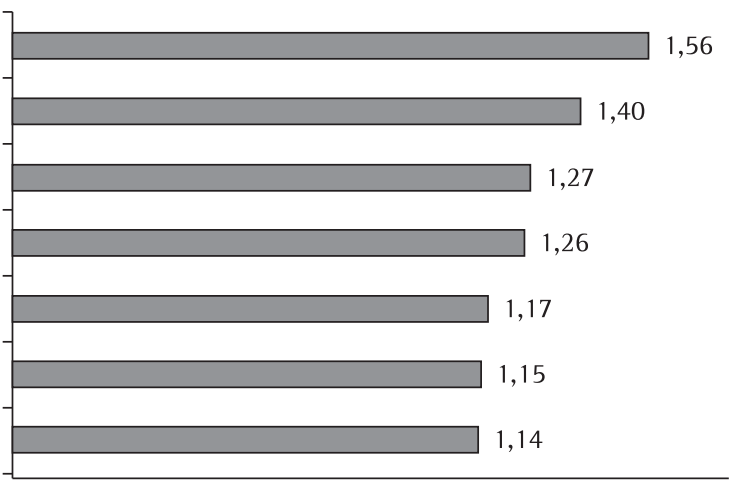

Figura 3. Priorização das características de qualidade segundo o Índice de Importância Técnica das Características da Qualidade Revisto $\left(1 Q_{j}^{*}\right)$ (recorte).

Quadro 4. Matriz dos procedimentos (recorte).

\begin{tabular}{|c|c|c|c|c|c|c|c|c|c|c|c|c|c|c|}
\hline Matriz dos procedimentos & 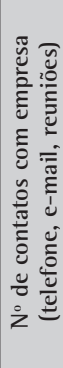 & 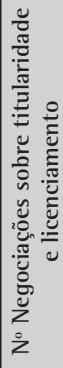 & 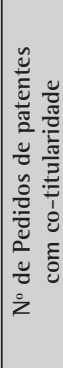 & 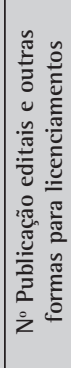 & 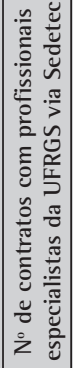 & 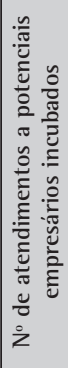 & 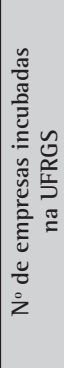 & 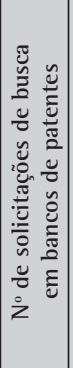 & 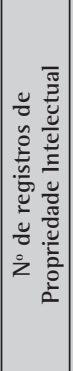 & 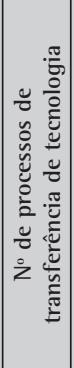 & 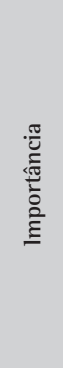 & 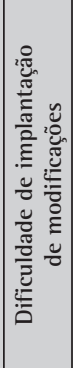 & 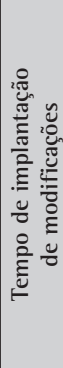 & 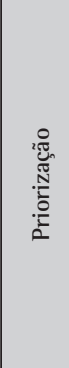 \\
\hline 1mportânica das $C Q s-1 Q_{j}^{*}$ & 1,40 & 0,74 & 1,56 & 1,26 & 0,82 & 1,17 & 1,27 & 0,92 & 1,15 & 1,14 & $I P_{i}$ & $F_{i}$ & $T_{i}$ & $I P_{i}^{*}$ \\
\hline $\begin{array}{l}\text { Realização de reuniões e contratos para } \\
\text { possibilidades de licenciamento }\end{array}$ & 9 & 9 & 9 & 9 & 3 & 3 & 3 & & 3 & 9 & 7,68 & 1 & 0,5 & 5,43 \\
\hline $\begin{array}{l}\text { Contato com especialistas para possibilidade } \\
\text { de consultoria e assessoria }\end{array}$ & 3 & & 3 & 3 & 9 & 9 & 3 & & & 3 & 5,01 & 1,5 & 2 & 8,68 \\
\hline $\begin{array}{l}\text { Atendimento de potenciais empresários - } \\
\text { empreendedores }\end{array}$ & 1 & 3 & 1 & 3 & 3 & 9 & 9 & & 1 & 9 & 5,47 & 1,5 & 1,5 & 8,21 \\
\hline Análise dos projetos de parceria & 3 & 9 & 9 & 3 & 3 & 3 & 9 & 3 & 9 & 9 & 8,22 & 1,5 & 1 & 10,07 \\
\hline $\begin{array}{l}\text { Recebimento das solicitações e realização } \\
\text { de busca em bancos de patente }\end{array}$ & & 9 & 3 & 3 & & 3 & 1 & 9 & 9 & & 4,85 & 2 & 1,5 & 8,40 \\
\hline $\begin{array}{l}\text { Análise de processos de transferência de } \\
\text { tecnologia }\end{array}$ & 3 & 9 & 9 & 9 & 3 & 3 & 3 & 3 & 9 & 9 & 8,13 & 1 & 1 & 8,13 \\
\hline $\begin{array}{l}\text { Realização de reuniões e contratos para } \\
\text { transferência de tecnologia }\end{array}$ & 9 & 9 & 9 & 3 & 1 & 3 & 3 & & 3 & 9 & 6,76 & 1,5 & 1 & 8,27 \\
\hline
\end{tabular}


Onde:

- $I P_{i}^{*}=$ Importância dos procedimentos revista;

- $I P_{i}=$ Importância dos procedimentos;

- $F_{i}=$ Avaliação da dificuldade de implantação do procedimento;

- $T_{i}=$ Avaliação do tempo de implantação do procedimento.

A Figura 4 apresenta os procedimentos considerados mais importantes para o atendimento das características de qualidade, conforme o Índice de Importância dos Procedimentos Revisto $\left(I P_{i}^{*}\right)$.

Conforme a Figura 4, verificou-se que a análise dos projetos de parceria, o contato com especialistas, as solicitações para a busca em bancos de patentes, a realização de reuniões e contratos para transferência de tecnologia são os procedimentos mais importantes para a efetivação da interação com a Universidade, seguidos pelo atendimento de potenciais empresários e pela análise dos processos de transferência de tecnologia.

\subsubsection{Matriz dos recursos humanos}

A matriz de recursos humanos foi realizada a fim de priorizar a importância de cada profissional da SEDETEC para realizar os procedimentos de prestação de serviços priorizados. A Equação 6 apresenta o cálculo da importância dos recursos tanto da matriz de recursos humanos como da matriz de infraestrutura.

$$
I R_{j}=\sum_{i=1}^{n} P R_{i j} \times I P_{i}^{*}
$$

Onde:

- $I R_{j}=$ Importância dos recursos humanos e de infraestrutura;

- $P R_{i j}=$ Grau de intensidade do relacionamento entre os procedimentos e os recursos humanos e de infraestrutura;

- $I P_{i}^{*}$ = Importância dos procedimentos revista.

A importância de cada profissional da SEDETEC para a realização dos procedimentos foi revista com base em dois índices: i) custos de Implantação $(C)$; e ii) dificuldade de Implantação $(L)$ de novos profissionais na equipe. Ambas as avaliações foram consideradas exclusivamente do ponto de vista gerencial. Foi utilizada uma escala de 0,5 a 2,0, variando de Custo muito alto $(0,5)$ a Custo baixo $(2,0)$ e Muito difícil $(0,5)$ a Fácil $(2,0)$ implantação, conforme apresenta a Equação 7.

$$
I R_{j}^{*}=I R_{j} \times \sqrt{C_{j}} \times \sqrt{L_{j}}
$$

Onde:

- $I R_{j}^{*}=$ Importância dos recursos humanos e dos itens de infraestrutura revista;

- $I R_{j}=$ Importância dos recursos humanos e dos itens de infraestrutura;

- $C_{j}=$ Custo de implantação dos recursos humanos e dos itens de infraestrutura;

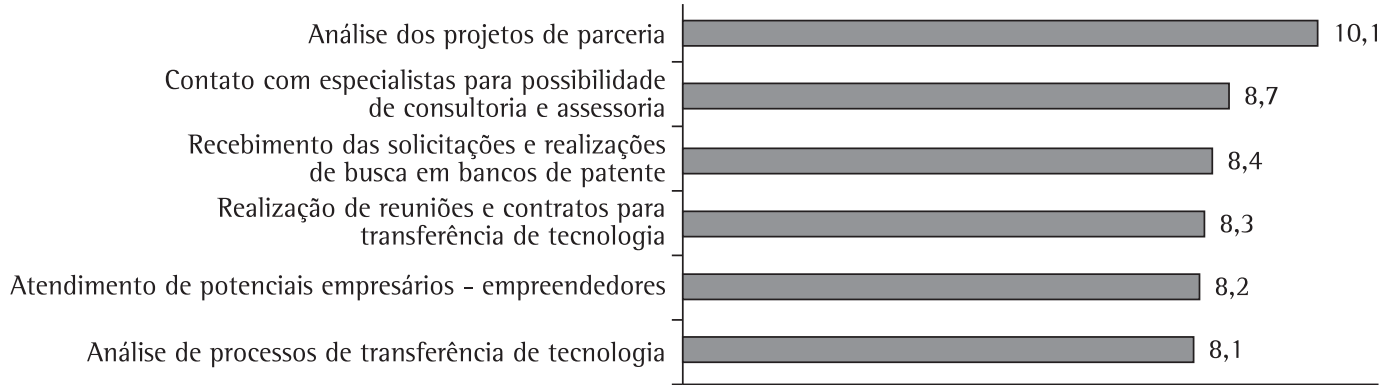

Figura 4. Priorização dos procedimentos (recorte).

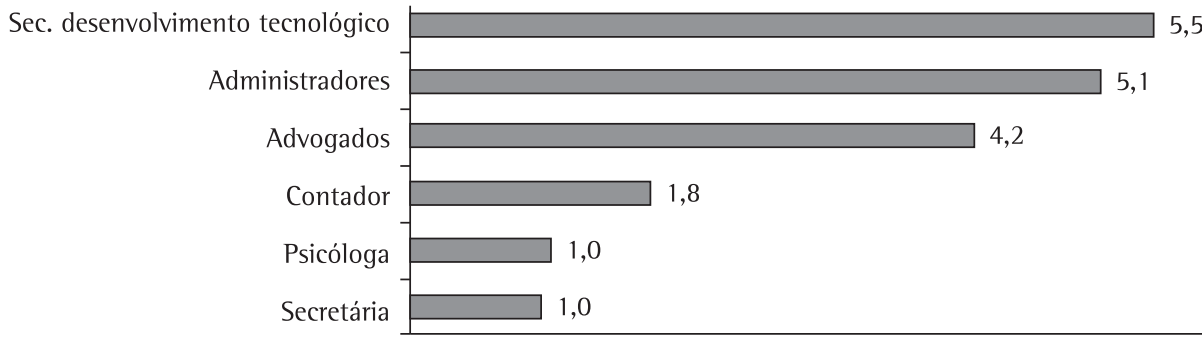

Figura 5. Priorização dos recursos humanos. 
- $L_{j}=$ Dificuldade de implantação dos recursos humanos e dos itens de infraestrutura.

$\mathrm{Na}$ Figura 5, verifica-se a priorização dos profissionais para realização dos procedimentos de prestação de serviços, conforme o índice de Importância dos Recursos Humanos Revisto $\left(I R_{j}^{*}\right)$.

Com base na Figura 5, verifica-se a importância do secretário de desenvolvimento tecnológico para a realização de cada procedimento, dada sua condição de gestor e tomador de decisão. No caso dos administradores, há o envolvimento em muitos procedimentos importantes, assim como dos advogados, que atuam direta ou indiretamente na execução de aproximadamente $90 \%$ dos procedimentos de maior importância.

\subsubsection{Matriz dos recursos de infraestrutura}

A matriz dos recursos de infraestrutura foi realizada a fim de priorizar os recursos de infraestrutura física e operacional necessários para a realização adequada dos procedimentos na prestação de serviços. A Figura 6 apresenta a priorização dos recursos, conforme o índice de Importância dos Recursos de Infraestrutura Revisto.

Conforme a Figura 6, a sala para advogados foi considerada um item prioritário para o atendimento dos procedimentos desenvolvidos pela SEDETEC, uma vez que em muitas etapas dos serviços é necessária a intervenção do setor jurídico, além de ser um local adequado para o tratamento de informações confidenciais. A rede lógica, a sala de reuniões e os demais itens operacionais asseguram um ambiente adequado para que sejam viabilizadas as tratativas de maneira formal e profissional.

\subsubsection{Matriz dos custos}

A matriz de custos foi elaborada a partir das matrizes de recursos humanos e de infraestrutura. Foi realizado um levantamento do custo mensal de cada recurso e distribuído ao longo de cada procedimento, de acordo com a intensidade do relacionamento indicado na respectiva matriz de recursos. Neste caso, os salários dos profissionais foram considerados com base em valores de mercado, e os custos de infraestrutura também consideraram valores aproximados de mercado (valores de referência de mercado e não conforme aplicados no orçamento da universidade).

A Figura 7 apresenta os custos totais dos profissionais envolvidos e da infraestrutura necessária para a realização dos procedimentos de prestação de serviços da SEDETEC e a importância de cada procedimento, demonstrando graficamente a relação custo x importância, que permite analisar se a alocação dos recursos está proporcional à importância dos procedimentos.

0 custo mensal de cada recurso humano foi calculado com base no produto da quantidade de pessoas em determinada função, do salário e do \% de tempo dedicado ao procedimento. 0 custo mensal de cada recurso de infraestrutura foi calculado com base no produto do custo de operação/manutenção, da quantidade e do \% de tempo dedicado a cada procedimento.

\subsection{Diretrizes para melhorias da qualidade dos serviços da SEDETEC}

Os resultados dos desdobramentos do QFD permitiram sugerir diretrizes de melhorias para a SEDETEC.

A partir da importância da qualidade demandada revista, a primeira demanda priorizada foi a ampla divulgação dos serviços que são realizados pela Secretaria, bem como das tecnologias existentes e das possibilidades de transferência de tecnologia entre a universidade e as empresas. A SEDETEC representa uma porta de entrada na UFRGS, a qual possui mecanismos para responder às demandas do setor produtivo, com possibilidades de prover soluções para a melhoria de produtos e processos por meio da transferência de tecnologia. Essa característica também implica em maior comunicação com seus clientes.

A divulgação de tecnologias disponíveis e de identificação de possibilidades de transferência para as empresas é realizada de maneira direcionada, pois, em geral, as empresas realizam contato, apresentam

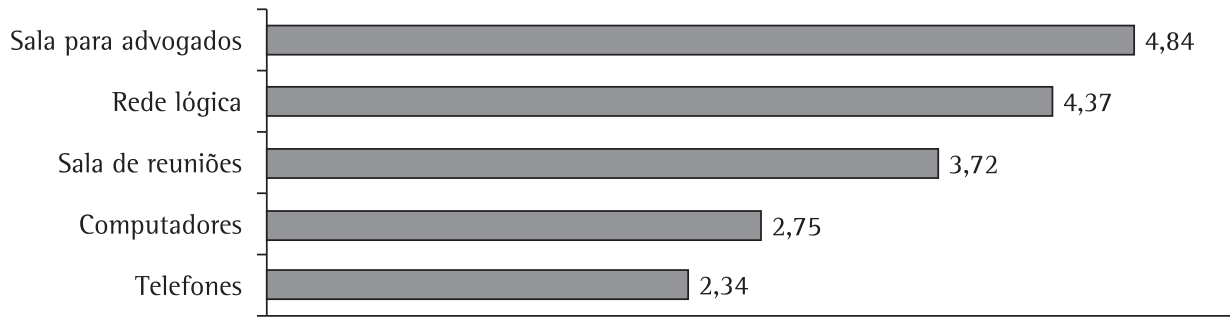

Figura 6. Relação de importância dos recursos de infraestrutura (recorte). 


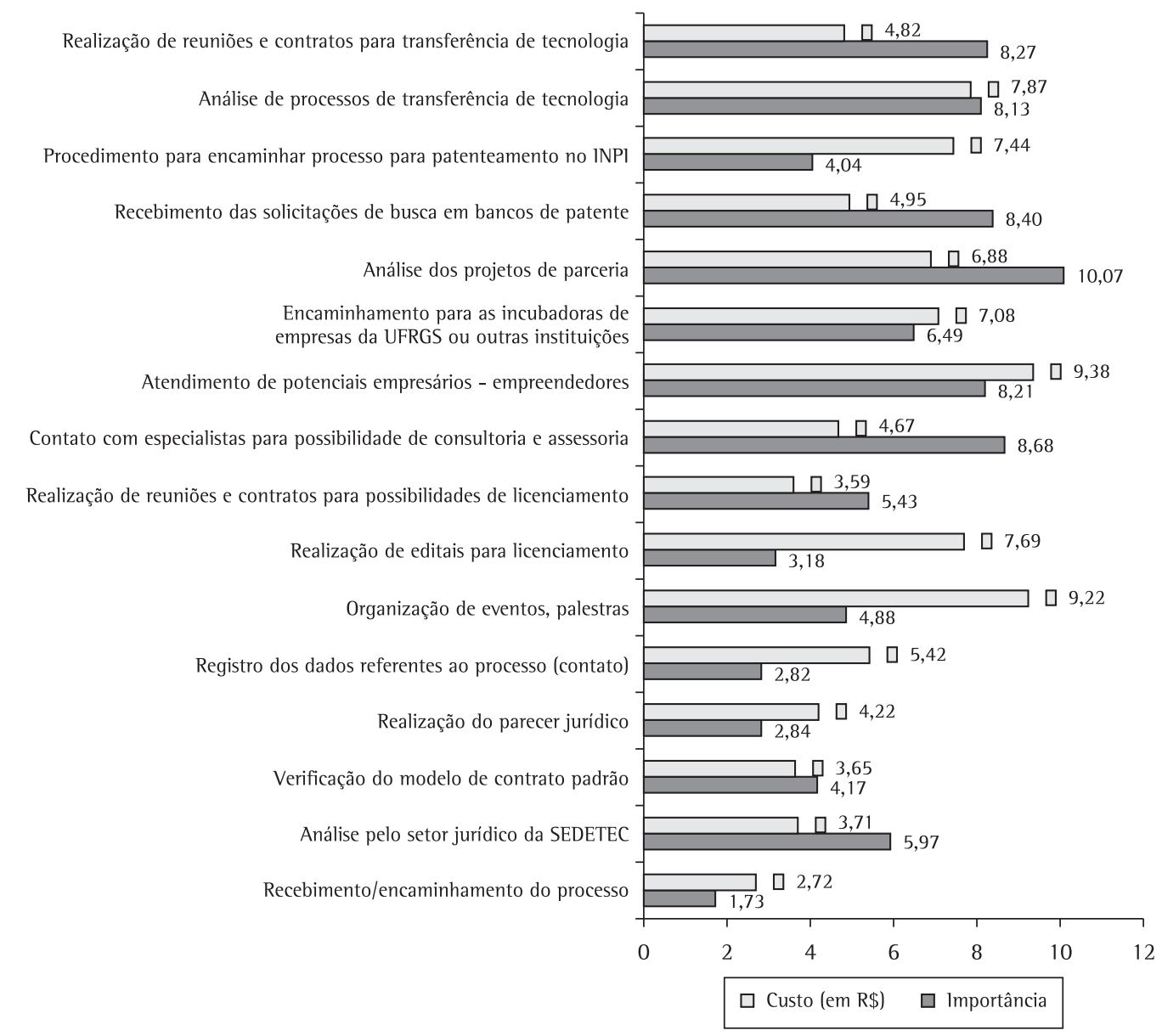

Figura 7. Relação de custo de recursos humanos e infraestrutura $\times$ importância dos procedimentos.

suas demandas e, em seguida, são verificadas as possibilidades de interação em função das competências da Universidade. Analisando-se o contexto, em especial, a partir da Lei de Inovação, percebe-se o desconhecimento sobre as potencialidades no desenvolvimento de parcerias e alianças com as Universidades por parte das empresas parceiras. Outra forma de acesso às tecnologias desenvolvidas pela UFRGS e à divulgação destas é por meio do atendimento a potenciais empresários que podem ingressar nas Incubadoras Tecnológicas da UFRGS, inclusive a partir da Maratona de Empreendedorismo, realizada anualmente pela SEDETEC.

Desta forma, uma das sugestões de melhoria seria ampliar e dinamizar as formas de comunicação, para divulgar e disseminar os benefícios e as potencialidades existentes na interação Universidade-Empresa, por meio da estrutura disponibilizada pela SEDETEC para efetivar as parcerias entre os agentes de inovação.

A segunda demanda priorizada foi a simplificação da relação entre Universidade-Empresa. A UFRGS atua sob a observância legal, tanto no âmbito da legislação federal como de normativas internas. Após a implantação da Lei de lnovação (Lei Federal n $\left.{ }^{\circ} 10.973 / 2004\right)$ (BRASIL, 2004) e da Decisão do CONSUN-UFRGS no 193/2011 e da Portaria n 2679/2011 (UNIVERSIDADE..., 2011a,b), ocorreu uma maior flexibilização e a simplificação dos processos de cooperação com empresas, sempre visando à ética e à transparência das relações, que são princípios essenciais da integridade pública.

$\mathrm{Na}$ Matriz da Qualidade, identificam-se as características de qualidade que devem ser monitoradas tais como o número de atendimentos a potenciais empresários incubados e o número de processos de transferência de tecnologia (conforme Figura 3). Assim, além das características atualmente monitoradas pela SEDETEC, sugere-se implantar um sistema de indicadores de desempenho que contemple as características priorizadas e apresentar aos clientes externos em seus relatórios.

A partir da Matriz de Procedimentos, priorizou-se o procedimento referente à análise de projetos e 
processos de transferência de tecnologia. Sugere-se a apreciação não apenas de aspectos jurídicos dos contratos de parceria, mas também uma análise de mercado. No caso de um resultado protegível, sugere-se identificar mercados além daquele em que a empresa parceira atua, podendo resultar em ganhos para ambos os envolvidos no projeto. Esse aspecto também poderia colaborar para alterar a imagem atual da SEDETEC, muito associada com atuação dos profissionais de direito, e buscar um equilíbrio com os demais profissionais que atuam na secretaria. A participação das decisões sobre os contratos de transferência de tecnologia e dos projetos de parceria propostos e analisados, bem como as solicitações de busca em bancos de patentes poderiam ser compartilhadas com profissionais de outras áreas. 0 contato com empresas e 0 atendimento a potenciais empresários também são relevantes e, para tanto, deve haver informações padronizadas e de conhecimento da maioria dos profissionais da SEDETEC.

No caso das Matrizes de Recursos Humanos e de Infraestrutura, para reduzir a importância atribuída ao Secretário de Desenvolvimento Tecnológico na atuação em todos os procedimentos, podem ser realizadas reuniões periódicas para a discussão das principais decisões entre a equipe, além de delegar autonomia para o desenvolvimento de alguns procedimentos. Para tanto, é necessário que a equipe esteja capacitada e treinada para realizar as atividades. Para a realização dos procedimentos necessários para o atendimento das características de qualidade demandadas, verifica-se a necessidade de profissionais com competências e habilidades específicas, elevando o custo dos profissionais, sendo importante a manutenção dos profissionais da equipe que já estão capacitados.

A Matriz de Custos apresenta a relação dos custos dos recursos envolvidos na realização dos procedimentos de acordo com sua importância. Neste aspecto, há alguns pontos nos quais o custo está acima da importância, tais como a organização de eventos e a publicação de editais de licenciamento. No entanto, estes procedimentos não podem ser desconsiderados pela sua importância estratégica na divulgação de informações e conceitos que implicam na interação Universidade-Empresa. A análise desta relação custo versus importância não deve estar desvinculada das estratégias da Secretaria.

\section{Conclusões}

0 estudo possibilitou a identificação das principais qualidades demandadas pelas empresas parceiras nas etapas do processo de interação Universidade-Empresa e propôs melhorias no serviço prestado pela Secretaria de Desenvolvimento Tecnológico (SEDETEC).
0 estudo contemplou três macro-etapas: i) realização da Pesquisa de Mercado com as empresas parceiras; ii) desdobramento das demandas de qualidade em requisitos do processo, utilizando o Modelo Conceitual do QFD proposto por Ribeiro, Echeveste e Danilevicz (2001); e iii) proposição de Diretrizes de melhorias para a SEDETEC.

Com a pesquisa de mercado, foi possivel identificar e priorizar as demandas de qualidade das empresas parceiras referentes às etapas de definição da instituição parceira e formalização da interação UniversidadeEmpresa. Nesta fase, foi possível verificar que a etapa de definição da instituição é priorizada pelas empresas. No entanto, o Quality Function Deployment (QFD) foi aplicado somente na etapa de formalização da interação Universidade-Empresa, por esta estar sob responsabilidade da SEDETEC.

Nessa etapa, a partir da Matriz da Qualidade, as demandas de qualidade referentes à etapa de formalização da interação foram desdobradas em características da qualidade ou requisitos do serviço prestado. As principais demandas de qualidade priorizadas foram: i) divulgação de tecnologias disponíveis para a transferência; ii) simplificação da relação; e iii) identificação das possibilidades de transferência de tecnologia para as empresas, tiveram a priorização revista. Em relação às características de qualidade, foram priorizadas: i) $n^{\circ}$ de pedidos de patentes em cotitularidade; ii) $n^{\circ}$ de contatos com empresas; iii) $n^{\circ}$ de empresas incubadas, apresentaram a priorização conforme importância técnica. Na matriz dos procedimentos, essas foram relacionadas com os procedimentos de prestação de serviços realizados para seu atendimento. Os procedimentos priorizados foram: i) análise dos projetos de parceria; ii) contato com especialistas; e iii) solicitações para a busca em bancos de patentes, como os procedimentos priorizados revistos. Nas matrizes de recursos humanos e de infraestrutura, os procedimentos foram relacionados com os recursos humanos e de infraestrutura necessários para a sua realização. Os recursos humanos priorizados na matriz de recursos humanos foram: i) o Secretário de Desenvolvimento Tecnológico; ii) os administradores; e iii) os advogados. E em relação à infraestrutura, foram priorizados: i) sala para advogados; ii) rede lógica; e iii) sala de reuniões. Por fim, na matriz de custos, foram estimados os custos envolvidos na realização dos procedimentos e relacionados com sua importância, permitindo analisar graficamente a relação custo do procedimento versus sua importância para o atendimento das qualidades demandadas. A partir dos desdobramentos destas demandas e a identificação dos principais procedimentos priorizados, foram apresentadas diretrizes de melhoria para a SEDETEC, sendo elas: 
- Reavaliar a atuação dos profissionais na equipe para uma possível atribuição de atividades que possam ser compartilhadas e complementadas pelas diferentes áreas de atuação, com a possibilidade de realizar treinamentos e capacitação específicos;

- Realizar um plano de comunicação e melhoria das ferramentas de divulgação, interna e externa, dos serviços realizados pela SEDETEC, para o melhor entendimento dos envolvidos no processo de interação;

- Viabilizar uma ferramenta que possa identificar as demandas do setor empresarial e associá-las com as competências da instituição e assim estimular a interação entre a Universidade e as empresas;

- Promover a divulgação das competências da instituição, bem como do banco de patentes (tecnologias protegidas) e outras tecnologias que possam ser transferidas para o setor produtivo.

Com a melhoria operacional dos procedimentos internos e da divulgação dos serviços e dos mecanismos de transferência de tecnologia existentes, espera-se aumentar a interação entre a UFRGS e empresas.

\section{Referências}

AKAO, Y. Manual de Aplicação do Desdobramento da Função Qualidade - QFD. Belo Horizonte: Fundação Christiano Ottoni, 1996. v. 1: Introdução ao Desdobramento da Qualidade.

AKAO, Y. Quality function deployment: integrating customer requirements into product design. Portland: Productivity Press, 1990. 369 p.

AlBUQUERQUE, E. M.; SILVA, L. A.; PÓVOA, L. Diferenciação intersetorial na Interação entre empresas e Universidades no Brasil. São Paulo em Perspectiva, v. 19, n. 1, p. 95-104, 2005. http://dx.doi.org/10.1590/S0102-88392005000100008

AMERICAN SUPPLIER INSTITUTE - ASI. Quality Function Deployment: implementation manual: 3-day workshop. Dearborn, ASI, 1993.

ASSOCIAÇÃO NACIONAL DE ENTIDADES PROMOTORAS DE EMPREENDIMENTOS INOVADORES - ANPROTEC; SEBRAE. Glossário dinâmico de termos na área de Tecnópolis, Parques Tecnológicos e Incubadoras de Empresas. Brasília: ANPROTEC, 2002

AYUP-ZOUAIN, R. N. Modelo de relacionamento Petrobrás com as instituições de $P \& D$ : redes temáticas e núcleos regionais. Porto Alegre, 2008. Slides.

BOUCHEREAU, V.; ROWLANDS, H. Methods and techniques to help quality function deployment (QFD). Benchmarking: An International Journal, v. 7, n. 1, p. 8-19, 2000.

BRASIL. Decreto $n^{\circ} 2.553$, de 11 de outubro 2005. Regulamenta a Lei no 10.973 , de 2 de dezembro de 2004 , que dispõe sobre incentivos à inovação e à pesquisa científica e tecnológica no ambiente produtivo, e dá outras providências. Diário Oficial da República Federativa do Brasil, Brasília, DF, 13 out. 2005. Disponível em: <http://www.planalto.gov.br/ccivil_03/_ato20042006/2005/Decreto/D5563.htm>. Acesso em: 09 jun. 2008.

BRASIL. Lei de lnovação Tecnológica n 10.973, de dezembro de 2004. Dispõe sobre incentivos à inovação e à pesquisa científica e tecnológica no ambiente produtivo e dá outras providências. Diário Oficial da República Federativa do Brasil, Brasília, DF, 03 dez. 2004. Disponível em: <http://www.planalto.gov. br/Ccivil_03/_Ato2004-2006/2004/Lei/L10.973.htm>. Acesso em: 09 jun. 2008.

BRATZ, M.; CATEN, C. S.; DANILEVICZ, A. M. F. Aplicação do QFD em serviços de consultas eletivas da Santa Casa de Porto Alegre.
In: ENCONTRO NACIONAL DE ENGENHARIA DE PRODUÇÃO ENEGEP-, 21., 2001, Salvador. Anais... . Salvador: ABEPRO, 2001. v. 1 , p. $1-8$.

CARNEVALL1, J. A.; CAUCHICK MIGUEL, P. A. Revisão, análise e classificação da literatura sobre o QFD - tipos de pesquisa, dificuldades de uso e benefícios do método. Gestão e Produção, v. 14, n. 3, p. 557-579, 2007. http://dx.doi.org/10.1590/S0104530X2007000300011

CARVALHO, M. M. QFD - Uma Ferramenta de Tomada de Decisão em Projeto. 1997. Tese (Doutorado em Engenharia de Produção)Universidade Federal de Santa Catarina, Florianópolis, 1997.

CAUCHICK MIGUEL, P. A. QFD no desenvolvimento de novos produtos: um estudo sobre a sua introdução em uma empresa adotando a pesquisa-ação como abordagem metodológica. Produção, v. 19, n. 1, p. 105-128, 2009.

CHENG, L. C.; MELO FILHO, L. D. R. QFD - Desdobramento da função qualidade na gestão de desenvolvimento de produtos. São Paulo: Editora Blücher, 2007.

CHENG, L. C.; SARANTÓPOULOS, 1. A. QFD in Brazil: A Successful Diffusion Process into Organizations. In: INTERNATIONAL SYMPOSIUM ON QUALITY FUNCTION DEPLOYMENT ISQFD, 1995, Tokyo. Proceedings... Tokyo: JUSE, 1995. p. 77-84.

CLAUSING, D. Total quality development: a step by step guide to world class concorrent engineering. New York: ASME press, 1994).

CLAUSING, D.; PUGH, S. Enhanced Quality Function Deployment. In: DESIGN AND PRODUCTIVITY INTERNATIONAL CONFERENCE, 1991 Honolulu. Proceedings... Honolulu: DPIC, 1991. p. 15-25.

CRIPPS, D. et al. University research: technology transfer and commercialization practices. Canberra: Australian Research Council, 1999. Commissioned Report 60.

CYSNE, F. P. Transferência de Tecnologia entre a Universidade e a Indústria. Encontros Bibli: Revista Eletrônica de Biblioteconomia e Ciência da Informação, n. 20, p. 54-74, 2005.

DAGNINO, R. A relação Universidade-Empresa no Brasil e o "argumento da hélice tripla”. Revista Brasileira de Inovação. FINEP, v. 2, n. 2, p. 367-307, 2003.

DAUSCHA, R. M. Inovação tecnológica nas empresas: panorama e estratégias para o Brasil. Disponível em: <http:// www2.desenvolvimento.gov.br/arquivo/publicacoes/sti/ indbraopodesafios/coletanea/tendenciastecnologicas/texto9ronalddauscha.pdf>. Acesso em: 09 jun. 2008.

EDQUIST, C. Systems of innovation: technologies, institutions and organizations. Routledge, 1997.

FELDAM, M. et al. Equity and the Technology Transfer Strategies of American Research Universities. Management Science INFORMS v. 48, n. 1, p. 105-121, 2002.

FERREIRA, A. M.; RIBEIRO, J. L. D. 0 uso do QFD no gerenciamento de projetos: um estudo de caso no setor de serviços. In: ENCONTRO NACIONAL DE ENGENHARIA DE PRODUÇÃO - ENEGEP, 15., 1995, São Carlos. Anais... . São Carlos: ABEPRO, 1995. v. 1, p. 507-512.

FREEMAN, C. The national system of innovation in historical perspective. Cambridge Journal of Economics. Cambridge, v. 19, n. 1, p. 5-24, 1995.

INSTITUTO NACIONAL DE PROPRIEDADE INDUSTRIAL - INPI. Disponível em: <http://www.inpi.gov.br/>. Acesso em: 09 ago. 2008.

KING, B. Better Designs in Half the Time: implementing QFD quality function deployment in AMÉRICA.3.ED. Methuen: GOAL/ QPC, 1989.

MARCHIORI, M. P.; COLENCI JUN1OR., A. Transferência de Tecnologia Universidade-Empresa - A Busca por Mecanismos de Integração Efetiva. In: ENCONTRO NACIONAL DE ENGENHARIA DE PRODUÇÃO - ENEGEP, 18.; CONGRESSO INTERNACIONAL DE ENGENHARIA INDUSTRIAL, 6., 1998, Niterói. Anais... ABEPRO, 1998. Disponível em: <http://www.abepro.org.br/ biblioteca/ENEGEP1998_ART482.pdf>. Acesso em: 18 abr. 2008.

MARCOVITCH, J. A cooperação da universidade moderna com o setor empresarial. Revista de Administração, v. 34, n. 4. p. 46-55., 1999. 
MENDONÇA, G. A. A. 0 desdobramento da função qualidade - QFD na melhoria da gestão na educação profissional no CEFETGO. In: CONGRESSO VIRTUAL BRASILEIRO DE ADMINISTRAÇÃO, 4., 2007. Anais... 2008. Disponível em: <http://www.convibra.com.br/2007/congresso/prem.asp>. Acesso em: 28 nov. 2008.

MORAES, C. A. C.; CAUCHICK MIGUEL, P. A. Uso do QFD na qualidade em serviços a partir dos dados de um programa de avaliação institucional: um estudo de caso em um curso de mestrado em engenharia de produção. In: ENCONTRO NACIONAL DE ENGENHARIA DE PRODUÇÃO - ENEGEP, 25., 2005, Porto Alegre. Anais... São Paulo: ABEPRO, 2005. v. 1, p. 1803-1810.

MOWERY, D.; SAMPAT, B. Universities in national innovation systems. In: FARGERBERG, J.; MOWERY, D.; NELSON, R. (Eds.). The Oxford Handbook of Innovation. Oxford University Press, 2005. p. 209-239.

N1OS1, J. 1999. Fourth-Generation R\&D: From Linear Models to Flexible Innovation. Journal of Business Research, v. 45, p. 111-117, 1999. http://dx.doi.org/10.1016/S0148-2963(97)00230-0

ORGANIZAČ̃̃O PARA COOPERAÇÃO E DESENVOLVIMENTO ECONỐMICO - OCDE. Manual de Oslo: Diretrizes para Coleta e Interpretação de Dados sobre Inovação. 3. ed. OCDE, Eurostat, FINEP, 1997

PEIXOTO, M. O. C.; CARPINETT1, L. R. Aplicação de QFD integrando o modelo de Akao e o modelo QFD estendido. Gestão e Produção (UFSCar), v. 5, n. 3, p. 221-237, 1998. http://dx.doi.org/10.1590/ S0104-530X1998000300005

PERKMANN, M.; WALSH, K. University-industry relationships and open innovation: Towards a research agenda. International Journal of Management Reviews, v. 9, n. 4, p. 259-280, 2007. http://dx.doi.org/10.1111/j.1468-2370.2007.00225.x

PÓVOA, L. M. C. Patentes de universidades e institutos públicos de pesquisa e a transferência de tecnologia para empresas no Brasil. 2008. Tese (Doutorado em Economia)-Universidade Federal de Minas Gerais, Belo Horizonte, 2008.

RIBEIRO, J. L. D.; CUNHA, M. G. ; ECHEVESTE, M. E. Desdobramento da qualidade: um plano de melhorias para retenção de clientes em clubes sociais e esportivo. In: ENCONTRO NACIONAL DE ENGENHARIA DE PRODUÇ̃̃O - ENEGEP, 21., 2001a, Salvador. Anais... . São Paulo: ABEPRO, 2001. v. 1, p. 1-9.

RIBEIRO, J. L. D.; ECHEVESTE, M. E.; DANILEVICZ, A. M. QFD Desdobramento da Função Qualidade. UFRGS, 2001b. (Série Monográfica).
SANTOS, L. A. C.; KOVALESK1, J. L.; PILATT1, L. A. Análise da Cooperação Universidade-Empresa como Instrumento para a Inovação Tecnológica. Revista Espacios. v. 29, n. 1, p. 12-29, 2008.

SEgAtT0, A. P. Análise do Processo de Cooperação Tecnológica Universidade - Empresa: Um Estudo Exploratório. 1996. Dissertação (Mestrado em Administração)-Universidade de São Paulo, São Paulo, 1996.

SEGATT0-MENDES, A. P. Teoria de Agência à Análise de Relações entre os Participantes dos Processos de Cooperação Tecnológica Universidade-Empresa. 2001. Tese (Doutorado em Administração)-Universidade de São Paulo, São Paulo, 2001.

SHANE, S. A. Academic entrepreneurship: University Spinoffs and Wealth Creation. Edward Elgar Publishing, 2004.

STAL, E. Cooperação Institucional Universidade-Empresa. Porto Alegre: Sebrae/RS, 1998.

SUZIGAN, W.; ALBUQUERQUE, E. M. A interação entre universidades e empresas em perspectiva histórica no Brasil. Belo Horizonte: UFMG/Cedeplar, 2008. Disponível em: <http://www.cedeplar. ufmg.br/pesquisas/td/TD\%20329.pdf>. Acesso em: 23 jun. 2008.

UNIVERSIDADE FEDERAL DO RIO GRANDE DO SUL - UFRGS. Conselho Universitário - ConsUn. Decisão n 193/2011, de 08 de abril de 2011a. Disponível em: < http://www.ufrgs.br/consun/ leis/Dec193_2011\%2820110503\%29.pdf >. Acesso em: 10 abr. 2011.

UNIVERSIDADE FEDERAL DO RIO GRANDE DO SUL - UFRGS. Gabinete do Reitor. Portaria $n^{o}$ 2679/2011, de 27 de maio de 2011b. Disponível em: <http://www.ufrgs.br/consun/leis/ Portaria_2679_2011.pdf >. Acesso em: 03 jun. 2011.

UNIVERSIDADE FEDERAL DO RIO GRANDE DO SUL - UFRGS. Gabinete do Reitor. Portaria $n^{\circ} 3064 / 1998$, de 05 de novembro de 1998. Disponível em: < http://www.sedetec.ufrgs.br/pagina/ eitt/download/portarias/portaria_n_3064.pdf >. Acesso em: 04 abr. 2008.

VASCONCELOS, M. C. R. L.; FERREIRA, M. A. T. A contribuição da cooperação universidade/empresa para o conhecimento tecnológico da indústria. Perspectivas em Ciência da Informação, v. 5, n. 2, p. 167-182, 2000.

VEDOVELLO, C. Science parks and university-industry interaction: geographical proximity between the agents as a driving force. Technovation, v.17, n. 9, p. 491-502, 1997. http://dx.doi. org/10.1016/S0166-4972(97)00027-8

\title{
Assessment of quality demand and guidelines for improving the University-Industry interaction process
}

\begin{abstract}
This paper presents the university-industry interaction process through which the Federal University of Rio Grande do Sul (UFRGS) is under the responsibility of the Secretary for Technological Development (SEDETEC). The purpose this article was to identify quality demands of the interaction process between UFRGS and partner companies, as well as to propose improvements to this process. Demands were identified through market research and then analyzed by means of the Quality Function Deployment (QFD), which provides insights for quality improvements. We then propose improvement actions to SEDETEC. Main results identify the quality demanded by the corporative segment, evaluate requirements and actions to achieve such quality demands, and propose improvement guidelines to the services provided by SEDETEC. Such improvements include a more dynamic communication system, a new set of indices for performance measurement, and procedures for analyzing market reaction due to the developed technologies.
\end{abstract}

\section{Keywords}

University-lndustry Interaction. Technological Transfer Office. QFD. 